\title{
Optimal Portfolio Choice When Utility Depends on Health
}

\author{
Ryan D. Edwards* \\ Assistant Professor of Economics \\ Queens College and the Graduate Center \\ City University of New York
}

April 13, 2009

*I am grateful to David Romer, Ronald Lee, Alan Auerbach, and seminar participants at UC Berkeley and elsewhere, and to several anonymous referees for helpful comments and suggestions. This research was partially supported by predoctoral training grants T32 AG00246-99, -00, and -01 from the National Institute on Aging. 


\begin{abstract}
This paper examines optimal portfolio choice when health can change the shape of the utility function. If adverse health shocks threaten to increase the marginal utility of consumption, that is, if they are Edgeworth-Pareto substitutes, risky health prompts individuals to lower their risky portfolio shares. Health naturally becomes more uncertain with age, so this theory may help explain why aging investors gradually decrease their risk exposure even when asset returns display no mean reversion and relative risk aversion is constant.

JEL classifications: G11, I12, J14
\end{abstract}

KEY WORDS: Background risk, cross partial derivative, health, precautionary saving, state-dependent utility 


\section{Introduction}

Portfolio decisions play an important role in wealth accumulation, accounting for perhaps 90 percent of total returns (Ibbotson and Kaplan, 2000). Because saving to finance consumption in retirement is an essential component of life-cycle behavior, so too is portfolio behavior. When viewed in the context of aging, a natural focal point is the role of time horizons. All things equal, advancing age leaves less time remaining before death, or a shortening investment horizon. Empirically speaking, both traditional investment advice (Malkiel, 1999) and observed portfolio shares (Ameriks and Zeldes, 2004; Guiso et al., 2002) suggest that risk taking declines with age. But whether this dynamic is sufficient to motivate declining exposure to risky assets through age is an open question theoretically.

In this paper, I examine the portfolio implications of health dynamics, which are also intrinsically linked to aging. I set up a theoretical model of portfolio choice with health status that can change the shape of the utility function, and I solve it analytically using log-linearization techniques pioneered by Viceira (2001) and Campbell and Viceira (2002). My results show that if health shocks affect the marginal utility of consumption, they have implications for portfolio choice. If investors expect they need more funds in poor health, to replace necessary home production that is lost, for example, they should hold safer financial portfolios. Since the chance of falling into poor health may increase with age, this mechanism may partially explain patterns of declining financial risk taking in age among retirees.

In the stylized model I consider, with independently and identically distributed (IID) returns and medical price inflation, and with preferences that display constant relative risk aversion (CRRA), the volatility of health prices and thus of health spending affects only the level of savings but not its composition. It seems likely that in a more realistic setting, portfolio choice might also respond to future cost uncertainty. In a companion paper, Edwards (2008) examines the empirical implications of uncertain health for portfolio choice.

To motivate my theoretical approach, which provides a convenient and intuitive closedform solution, I first discuss previous efforts in portfolio choice and the role of time horizons in 
particular. Section 2 also includes a discussion of relevant literature in health economics and precautionary saving. Then in Section 3, I set up and solve a multi-period model of portfolio choice with risky health in the utility function, and I discuss the model's implications for saving and portfolio choice. Section 4 addresses how these results may change under less stylized conditions and discusses issues of broader context.

\section{Background}

\subsection{Portfolio choice and time horizons}

Two key ingredients in modeling portfolio choice are the structure of preferences and the behavior of asset returns. Time-separable power utility is common in macroeconomics and finance because it encapsulates constant relative risk aversion. Individuals with CRRA preferences will not alter their relative demands for risky assets based on how much income or wealth they have, which is consistent with stationary average asset returns over time (Campbell and Viceira, 2002).

The nature of asset returns is a more opaque topic. The baseline assumption that returns are IID grew out of the theory of no financial arbitrage and a long track record of poor predictions. But researchers have sometimes identified empirical departures from IID returns (Siegel, 1994; Campbell et al., 1997; Campbell and Viceira, 2002), although their precise causes remain unclear. Traditional wisdom certainly places considerable weight on the ability to ride out a bad market. Still, most models of portfolio choice are based on the assumption that returns are IID because of its theoretical appeal (Merton, 1969, 1971; Samuelson, 1969, 1989; Jagannathan and Kocherlakota, 1996; Elmendorf and Kimball, 2000; Viceira, 2001; Campbell and Viceira, 2002; Cocco et al., 2005). Power utility and IID stock returns together imply the classic result that long-term investors ought to behave "myopically," so that the optimal risky share should remain constant through time. Portfolio choice over many periods or an infinite horizon is actually the same as portfolio choice over only one period. 
This baseline result can change in the presence of "background risk" (Heaton and Lucas, 2000), such as may derive from risky labor income, business wealth, or other elements. Kimball (1992) coins the term "temperance" to describe reduced financial risk taking in response to other uncorrelated risks, while Gollier and Pratt (1996) term it "risk vulnerability" and reveal that most standard utility functions display it. Much theoretical work has considered the impact of labor income on portfolio choice, typically finding that young workers should invest their assets more riskily than old retirees because their future labor income acts as a hedge against financial market fluctuations (Jagannathan and Kocherlakota, 1996; Viceira, 2001). But this insight cannot explain the continuous declines in risky portfolio shares with age after retirement that are in the data.

\section{$2.2 \quad$ Financial implications of health}

Retirees face risks associated with their health status, a fact that previous theoretical models have not emphasized. Out-of-pocket medical spending is clearly one such risk, given the gaps in Medicare coverage and the means-testing of Medicaid. Smith (1999) shows that health spending is not large on average among U.S. retirees, but French and Jones (2004) reveal that it is serially correlated and with low probability can be catastrophically large. Several papers in the precautionary saving literature reveal a link between the risk of future health expenditures and increased saving (Hubbard et al., 1994; Palumbo, 1999; Dynan et al., 2004).

Empirical studies of portfolio choice have revealed that current health status seems to be correlated with the degree of financial risk taking. Guiso et al. (1996) find that Italian households headed by individuals who spent more days sick tended to hold safer financial portfolios, even after controlling for many other variables. Rosen and $\mathrm{Wu}$ (2004) show a robust association between low health status and safe portfolios among households approaching retirement in the Health and Retirement Study. What is interesting about these studies is that health insurance coverage and medical expenditures do not seem to explain much of the connection between health status and risky portfolio shares. 


\subsection{Health and the cross partial}

A less obvious channel than medical expenditure is that of health status affecting utility directly, making other consumption more or less dear. Formally, if health enters the utility function, it may exhibit some degree of Edgeworth-Pareto complementarity (Samuelson, 1974), so that the cross partial derivative of utility, $U$, with respect to consumption, $C$, and health, $H$, or $\partial^{2} U / \partial C \partial H$, is nonzero. That is, declines in health could either increase or decrease the demand for money.

How might this work, and in which direction? When sick, the enjoyment derived from certain goods and services is likely to fall. A classic example would be delaying a ski vacation after breaking a leg. Many types of health shocks may reduce enjoyment and thus marginal utility in this manner. But debilitating conditions can push the demand for money in the opposite direction if poor health inhibits home production of necessary goods and services. A broken leg may require hiring taxis instead of walking, or ordering food delivered instead of shopping for and preparing it. The latter channel is surely affected by household structure; a healthy spouse or child can replace lost home production.

Evidence on the sign of the cross partial is mixed and suggests that it could be different at different ages or for different age-specific health conditions. Viscusi and Evans (1990) find that chemical workers expect their marginal utilities of income to decline in bad health as a result of job risks. Evans and Viscusi (1991) report that temporary health conditions like burns and poisonings resulting from unsafe consumer goods seem not to affect the marginal utilities of surveyed adults. Lillard and Weiss (1997) find that among elderly households in the Retirement History Survey, adverse health shocks raise the marginal utility of consumption, inducing transfers from the healthy to the sick partner. In a recent paper, Finkelstein et al. (2008) recover a positive cross partial among elderly and near-elderly individuals in the Health and Retirement Study.

In this paper, I focus on the implications for life-cycle portfolio choice of a cross partial that is nonzero. My results reveal that a negative cross partial is most consistent with 
empirical patterns of portfolio shares, which I examine separately in Edwards (2008). A positive cross partial would operate as a hedge against future risks to health, and in my model it implies that risk taking should increase with age, other things equal. This effect is nonexistent in the data, so it must either be theoretically incorrect or overwhelmed by other influences. Another problem with a positive cross partial, i.e. if consumption and health were Edgeworth-Pareto complements, is identified by Bommier and Stecklov (2002). They point out that when the cross partial is positive, social welfare would be maximized when the poorest were also the sickest, a situation that directly conflicts with stated social goals for health.

\subsection{Health, wealth, and causality}

As originally envisioned in the seminal work of Grossman (1972), health is an endogenous variable, a function of past endowments, depreciation, and investments both past and present. Thus far and in the stylized theoretical model I will present in Section 3, I have treated health as though it were exogenously determined. Although this is fairly standard in the literature on financial decision making, a perfectly relevant question is whether this may bias my results.

Picone et al. (1998) use a modified Grossman model to examine precautionary saving both in the traditional sense and in the form of health investments when the onset of illness is uncertain. Based on their work, it appears that formally modeling health capital could attenuate but is unlikely to nullify my findings. When health itself is the risky asset, it makes more intuitive sense to engage in precautionary health investment than to save money. But Picone et al. find that saving decisions typically also react to health uncertainty when utility is Cobb-Douglas over consumption and health. The effect is amplified when individuals are more "risk averse" in their terminology, which translates into having a large negative rather than small positive cross partial.

Less clear is whether a richer model that allowed for the direct hedging of risky health 
through less risky healthy behaviors would still find portfolio responses. It is clear that choices not to smoke, not to be obese, and so on are available and effective in reducing health risks. But if one is willing to believe that enough risks to health are exogenous to the individual, such as must be the case with many forms of cancer for example, complete hedging is probably impossible.

\section{A multi-period model of portfolio choice in the pres- ence of health risk}

This section develops and solves a theoretical model of portfolio choice based on the work of Viceira (2001) and Campbell and Viceira (2002). The setup is as follows. There are two types of infinitely-lived investors with Cobb-Douglas preferences over consumption and health. Type $h$ is healthy and endowed with health but perceives a periodic risk, $\pi_{h} \in(0,1)$, of permanently becoming type $u$, unhealthy and having to purchase health. It will turn out that type $h$ investors react to $\pi_{h}$ by decreasing their risky portfolio share, which is shown by Proposition 2 and is the key insight of the model. Unhealthy type $u$ investors are in the absorbing state and thus technically face no uncertainty. But for them, $\pi_{h}$ is essentially 1 ; they are fully exposed to health risk and therefore hold the safest financial portfolios.

In reality, individuals transit in and out of poor health over time, and the probability of entering poor health increases with age while the probability of escaping surely decreases. Edwards (2008) addresses some of these issues directly when gauging the model's fit to crosssectional data, where $\pi_{h}$ and portfolio shares vary widely across individuals. Modeling $\pi_{h}$ more realistically would significantly if not fully impede finding an analytical solution, as is typically the case in the precautionary saving literature. As I discuss in Section 4, the main qualitative implications of my model are largely unaffected by the assumption that $\pi_{h}$ is fixed, but a known trajectory of $\pi_{h}$ through age will alter results in a relatively standard and intuitive way. 


\subsection{Preferences}

I model preferences in a standard fashion, as time-separable over an infinite horizon with a constant discount factor, $\delta$ :

$$
\mathcal{U}=\sum_{s=0}^{\infty} \delta^{s} \cdot U_{s}\left(C_{s}, H_{s}\right)
$$

Following Picone et al. (1998), suppose investors have nonseparable Cobb-Douglas tastes over health, $H_{t}$, and consumption, $C_{t}$ :

$$
U_{t}\left(C_{t}, H_{t}\right)=\frac{\left(C_{t}^{\psi} H_{t}^{1-\psi}\right)^{1-\gamma}}{1-\gamma}
$$

where $\psi \in(0,1)$ and $\gamma>0$. Restricting the exponents on $C_{t}$ and $H_{t}$ to sum to unity fixes a unique $\gamma$, which could otherwise simply be rescaled. To ensure that marginal utilities of both goods are positive and decreasing in their arguments, $\gamma>0$ and $\psi \in(0,1)$.

\subsection{The budget constraint and technology}

For ease of exposition, I assume that health cannot be saved between periods; it is either endowed or must be purchased, and it is immediately consumed. This assumption probably amplifies the effect of health risk on portfolio choice, because individuals cannot build a precautionary stock of health to lessen the potential impact of future health shocks. But as I discussed in Section 2, risky health typically affects non-health consumption even in richer models with health capital (Picone et al., 1998).

Healthy type $h$ individuals are endowed with health $H_{t}^{h}$ that grows at an exogenous rate $g: H_{t+1}^{h}=H_{t}^{h} e^{g}$, and they are prohibited from buying or selling health. Each period, unhealthy type $u$ individuals must purchase their health. Those of type $h$ face a probability $\pi_{h} \in[0,1)$ each period of permanently becoming type $u$.

Although preferences are uniform across states, the budget constraint is not. There is no labor income, and all investors earn a total return on their financial portfolios equal to 
$R_{p, t+1}>0$. Healthy investors of type $h$ are endowed with health and face

$$
W_{t+1}=\left(W_{t}-C_{t}^{h}\right) R_{p, t+1},
$$

while unhealthy type $u$ investors must purchase health at price $P_{h, t}>0$ :

$$
W_{t+1}=\left(W_{t}-C_{t}-P_{h, t} H_{t}\right) R_{p, t+1} .
$$

Individuals can distribute their wealth between two financial assets. One asset is risky, with total return given by $R_{1, t+1} \equiv e^{r_{1, t+1}}$, where $r_{1, s}$ is IID. The other asset generates a certain return $R_{f} \equiv e^{r_{f}}$, where $r_{f}$ is a constant parameter. The return on the financial portfolio, $R_{p, t+1}$, is therefore

$$
R_{p, t+1}=\alpha_{t} R_{1, t+1}+\left(1-\alpha_{t}\right) R_{f},
$$

where $\alpha_{t}$ is the share of wealth held in the risky asset at time $t$. The expected excess $\log$ return, $E_{t} r_{1, t+1}-r_{f}$, is constant, and the unexpected excess log return is conditionally homoscedastic, serially uncorrelated, and normally distributed with mean zero and variance $\sigma_{r}^{2}$. It is analytically convenient to model $P_{h, t}$ as lognormal:

$$
P_{h, t}=\Pi_{s=\tau}^{t} R_{h, s},
$$

where the $R_{h, s} \equiv e^{r_{h, s}}$ are lognormal IID health-inflation rates. It is realistic to assume they are independent of asset returns: $\operatorname{Cov}_{t}\left[r_{h, t+1}, r_{1, t+1}\right]=0$. Under these conditions, it turns out that the price of health, $P_{h, t}$ affects saving but not portfolio choice in this model. Mathematically, this is because terms involving the health price cancel out of the first-order conditions when $P_{h, t}$ is uncorrelated with asset returns. Intuitively, investors with CRRA preferences only care about relative risk, so portfolio choice is only affected by risk aversion and the characteristics of the optional risky asset. 


\subsection{Solving the model}

The individual's problem is to

$$
\max _{C_{t}, H_{t}, \alpha_{t}} \mathcal{U}, \quad \forall t
$$

subject to the expected budget constraint, (3) or (4). I follow Viceira (2001), and Campbell and Viceira (2002) in searching for the model's approximate log-linear solution. I linearize the budget constraints, (3) and (4), by taking first-order Taylor approximations around the mean log ratios of consumption and wealth, and of health spending and wealth. As shown in Appendix A, if these means are stable, then the budget constraints are

$$
w_{t+1}-w_{t}=k^{h}-\rho_{c}^{h}\left(c_{t}^{h}-w_{t}\right)+r_{p, t+1},
$$

for healthy investors, and

$$
w_{t+1}-w_{t}=k-\rho_{c}\left(c_{t}-w_{t}\right)-\rho_{h}\left(h_{t}+\sum_{s=0}^{t} r_{h, s}-w_{t}\right)+r_{p, t+1}
$$

for unhealthy investors, where lowercase variables represent logs. The $k$ 's and $\rho$ 's are constants, all the $\rho$ 's are positive, and $r_{p, t+1}$ is the approximate log return on the financial portfolio, derived by Campbell and Viceira (1999):

$$
r_{p, t+1} \approx \alpha_{t} r_{1, t+1}+\left(1-\alpha_{t}\right) r_{f}+\frac{1}{2} \alpha_{t}\left(1-\alpha_{t}\right) \sigma_{r}^{2} .
$$

To proceed, I assume joint lognormality in consumption and asset returns (Hansen and Singleton, 1983), determine log-linearized Euler equations, and then combine them with the budget constraints and guesses about optimal consumption rules. I am interested in the portfolio choices of healthy investors, but this requires that I first solve for the behavior of unhealthy investors. 


\subsubsection{Optimal choices of unhealthy investors}

When unhealthy, individuals must purchase their health each period, solving (7) subject to (4). With two goods in the utility function, there are two Euler conditions that must be satisfied:

$$
1=E_{t}\left[\delta\left(\frac{C_{t+1}}{C_{t}}\right)^{\psi(1-\gamma)-1}\left(\frac{H_{t+1}}{H_{t}}\right)^{(1-\psi)(1-\gamma)} R_{i, t+1}\right]
$$

and

$$
1=E_{t}\left[\delta \frac{1}{R_{h, t+1}}\left(\frac{H_{t+1}}{H_{t}}\right)^{(1-\psi)(1-\gamma)-1}\left(\frac{C_{t+1}}{C_{t}}\right)^{\psi(1-\gamma)} R_{i, t+1}\right],
$$

for $i=1, f, p$ and where the price of health follows the process described by (6). Both Euler equations must hold for each asset $i=1, f$ that is held by the investor, and for the portfolio, $p$. When all of the variables inside the expectations operators are lognormal, the Euler equations can be log-linearized exactly, as described in Appendix B:

$$
\begin{aligned}
\log \delta & +E_{t}\left[r_{i, t+1}\right]+\beta_{1} E_{t}\left[c_{t+1}-c_{t}\right]+\beta_{2} E_{t}\left[h_{t+1}-h_{t}\right] \\
& +\frac{1}{2} \operatorname{Var}_{t}\left[r_{i, t+1}+\beta_{1}\left(c_{t+1}-c_{t}\right)+\beta_{2}\left(h_{t+1}-h_{t}\right)\right]=0,
\end{aligned}
$$

and

$$
\begin{aligned}
\log \delta & +E_{t}\left[r_{i, t+1}\right]-E_{t}\left[r_{h, t+1}\right]+\beta_{3} E_{t}\left[h_{t+1}-h_{t}\right]+\beta_{4} E_{t}\left[c_{t+1}-c_{t}\right] \\
& +\frac{1}{2} \operatorname{Var}_{t}\left[r_{i, t+1}-r_{h, t+1}+\beta_{3}\left(h_{t+1}-h_{t}\right)+\beta_{4}\left(c_{t+1}-c_{t}\right)\right]=0
\end{aligned}
$$

where $\beta_{1}=\psi(1-\gamma)-1, \beta_{2}=(1-\psi)(1-\gamma), \beta_{3}=(1-\psi)(1-\gamma)-1$, and $\beta_{4}=\psi(1-\gamma)$.

Solving the model requires guesses about the optimal consumption rules. Individuals with Cobb-Douglas preferences over consumption and health will split resources evenly between

them. Instead of a single rule targeting a consumption-wealth ratio, which is standard when 
there is one good, there are now two rules:

$$
c_{t}=b_{c, 0}^{u}+b_{c, 1}^{u} w_{t}
$$

and

$$
h_{t}+\sum_{s=0}^{t} r_{h, s}=b_{h, 0}^{u}+b_{h, 1}^{u} w_{t} .
$$

These rules allow consumption and health costs to have separate wealth elasticities, $b_{s, 1}^{u}$ for $s=c, h$. Combining the log-linearized Euler conditions, the log-linearized budget constraint, and the optimal rules allows us to solve for the behavior of unhealthy investors.

Proposition 1. Unhealthy individuals invest a share $\alpha_{t}^{u}$ of their wealth in the risky asset that is given by

$$
\alpha_{t}^{u}=\frac{E_{t}\left[r_{1, t+1}\right]-r_{f}+\frac{1}{2} \sigma_{r}^{2}}{\gamma \sigma_{r}^{2}} .
$$

The optimal rules are

$$
c_{t}=b_{c, 0}^{u}+w_{t}
$$

and

$$
h_{t}+\sum_{s=0}^{t} r_{h, s}=b_{h, 0}^{u}+w_{t},
$$

where $b_{c, 0}^{u}$ and $b_{h, 0}^{u}$ are constants given by (59)-(60) that represent the target consumptionwealth and health-wealth ratios.

Proof. See Appendix C.

The portfolio rule (17) looks the same as the Merton (1969) rule for investors who have risk aversion over consumption equal to $\gamma$. Intuitively, this is because unhealthy investors must purchase health as well as consumption, exposing the enjoyment of both to returns uncertainty. Since preferences are Cobb-Douglas, expenditure shares will be stable and $C_{t}=a \cdot H_{t}$ for some $a$. Then relative risk aversion $\mathcal{R}_{C}=-C \cdot U_{C C} / U_{C}=\gamma$. That is, total risk aversion for the unhealthy investor is effectively $\gamma$ here. Proposition 2 will show that as 
long as $\gamma>1$, healthy investors who face health risk $\pi_{h} \in[0,1)$ have effective risk aversion lower than $\gamma$, so they set their risky portfolio share $\alpha_{t}^{h}$ higher than do unhealthy investors.

\subsubsection{Optimal choices of healthy investors facing health risk}

Healthy individuals face a constant probability $\pi_{h} \in(0,1)$ each period of becoming permanently unhealthy. They can only choose consumption and portfolio shares, so they follow a single Euler condition in consumption:

$$
\begin{aligned}
1= & E_{t}\left[\left(1-\pi_{h}\right) \delta\left(\frac{C_{t+1}^{h}}{C_{t}^{h}}\right)^{\psi(1-\gamma)-1}\left(\frac{H_{t+1}^{h}}{H_{t}^{h}}\right)^{(1-\psi)(1-\gamma)} R_{i, t+1}\right] \\
+ & E_{t}\left[\pi_{h} \delta\left(\frac{C_{t+1}}{C_{t}^{h}}\right)^{\psi(1-\gamma)-1}\left(\frac{H_{t+1}}{H_{t}^{h}}\right)^{(1-\psi)(1-\gamma)} R_{i, t+1}\right],
\end{aligned}
$$

for $i=1, f, p$ as before, and where the expectations operator has already been distributed between the two additive parts of the Euler equation. Since (20) is a sum of expectations of lognormal variables, simply taking logs of both sides will not work. Appendix B shows how two Taylor expansions result in the following approximate log-linear Euler equation in the healthy state, where the $\beta$ 's are defined as in (13) and (14):

$$
\begin{aligned}
0= & \log \delta+E_{t}\left[r_{i, t+1}\right]+\left(1-\pi_{h}\right) \beta_{1} E_{t}\left[c_{t+1}^{h}-c_{t}^{h}\right] \\
& +\left(1-\pi_{h}\right) \beta_{2} E_{t}\left[h_{t+1}^{h}-h_{t}^{h}\right] \\
& +\frac{1-\pi_{h}}{2} \operatorname{Var}_{t}\left[r_{i, t+1}+\beta_{1}\left(c_{t+1}^{h}-c_{t}^{h}\right)+\beta_{2}\left(h_{t+1}^{h}-h_{t}^{h}\right)\right] \\
& +\pi_{h} \beta_{1} E_{t}\left[c_{t+1}-c_{t}^{h}\right]+\pi_{h} \beta_{2} E_{t}\left[h_{t+1}-h_{t}^{h}\right] \\
& +\frac{\pi_{h}}{2} \operatorname{Var}_{t}\left[r_{i, t+1}+\beta_{1}\left(c_{t+1}-c_{t}^{h}\right)+\beta_{2}\left(h_{t+1}-h_{t}^{h}\right)\right] .
\end{aligned}
$$

Healthy investors have one state variable and one consumption rule:

$$
c_{t}^{h}=b_{c, 0}^{h}+b_{c, 1}^{h} w_{t} .
$$


To solve for the behavior of healthy investors, I can combine this rule, the log-linear Euler approximation, the budget constraints, and Proposition 1.

Proposition 2. Healthy individuals invest a share $\alpha_{t}^{h}$ of their wealth in the risky asset that is given by

$$
\alpha_{t}^{h}=\frac{E_{t}\left[r_{1, t+1}\right]-r_{f}+\frac{1}{2} \sigma_{r}^{2}}{R\left(\psi, \gamma, \pi_{h}\right) \cdot \sigma_{r}^{2}}
$$

where

$$
R\left(\psi, \gamma, \pi_{h}\right)=1-(1-\gamma)\left(\psi+(1-\psi) \pi_{h}\right)
$$

is the healthy investor's effective risk aversion, a function of the preference parameters and $\pi_{h} \in(0,1)$, the probability that the individual will become permanently unhealthy next period. The optimal consumption rule is

$$
c_{t}^{h}=b_{c, 0}^{h}+w_{t}
$$

where $b_{c, 0}^{h}$ is the target consumption-wealth ratio.

Proof. See Appendix D.

Equation (23) is the main result of the model, and I discuss its implications in greater detail below. In the special case of $\pi_{h}=1$, effective risk aversion $R(\cdot)=\gamma$ and $(23)$ reduces to (17). That is, when the healthy investor faces full exposure to purchasing health, risk aversion and the portfolio share are the same as those of unhealthy investor.

\subsection{Implications}

\subsubsection{Precautionary saving}

Target ratios of consumption and health to wealth, the $b_{s, 0}$ 's in (18), (19), and (25), determine saving behavior in this model. Appendix $\mathrm{C}$ shows that unhealthy investors lower $b_{c, 0}^{u}$ and $b_{h, 0}^{u}$ and thus increase precautionary saving if the volatility of asset returns or of health price inflation increases. These findings are consistent with those of Lillard and Weiss 
(1997) and Palumbo (1999), who estimate large effects of medical expenditure uncertainty on precautionary saving.

Saving by healthy investors is different, since their behavior is contingent on optimal choices when unhealthy. Appendix D shows that increased financial risk may increase or decrease saving while healthy, depending on the magnitude of precautionary saving in the unhealthy state. Health price volatility actually decreases saving when healthy because it does not affect anything but saving when unhealthy, which rises. The effect of health risk, $\pi_{h}$, on saving while healthy is of indeterminate sign.

\subsubsection{Portfolio choice}

Risky portfolio shares $\alpha^{u}$ and $\alpha^{h}$ in (17) and (23) are different only insofar as the healthy investor's effective risk aversion, $R\left(\psi, \gamma, \pi_{h}\right)$, differs from $\gamma$, the effective risk aversion of the unhealthy investor. Volatility in health prices has no effect on portfolio choice because it is uncorrelated with market risk and thus has no effect on the relative attractiveness of the risky asset.

The properties of $R\left(\psi, \gamma, \pi_{h}\right)$ depend critically on whether $\gamma \gtrless 1$. If $\gamma>1$, simple algebra shows that since $\pi_{h}<1$,

$$
\begin{aligned}
\psi+(1-\psi) \pi_{h} & <1 \\
(1-\gamma)\left(\psi+(1-\psi) \pi_{h}\right) & >1-\gamma \\
R\left(\psi, \gamma, \pi_{h}\right)=1-(1-\gamma)\left(\psi+(1-\psi) \pi_{h}\right) & <\gamma,
\end{aligned}
$$

which states that effective risk aversion is lower for the healthy investor than for the unhealthy investor. It follows that

$$
\alpha^{h}>\alpha^{u}
$$


as long as the equity risk premium is positive. It also follows from (26) that

$$
\frac{\partial R\left(\psi, \gamma, \pi_{h}\right)}{\partial \pi_{h}}=(\gamma-1)(1-\psi)>0
$$

and

$$
\frac{\partial \alpha^{h}}{\partial \pi_{h}}=-\frac{E_{t}\left[r_{1, t+1}\right]-r_{f}+\frac{1}{2} \sigma_{r}^{2}}{\sigma_{r}^{2}} \cdot \frac{1}{R^{2}} \cdot \frac{\partial R}{\partial \pi_{h}}<0 .
$$

Thus if $\gamma>1$ and the equity risk premium is positive, an increase in health risk increases the effective risk aversion and decreases the optimal risky portfolio share of the healthy investor.

But if instead $0<\gamma<1$, the inequalities in (26)-(29) are all reversed, as are the model's implications for portfolio behavior in the presence of health risk. When $\gamma=1$ exactly, $R\left(\psi, 1, \pi_{h}\right)=1=\gamma$ and health risk has no effect on portfolio choice at all. Thus the model's predictions for portfolio choice hinge crucially on the level of $\gamma$. This is no accident, because $\gamma$ determines the sign of the cross partial derivative of utility:

$$
\frac{\partial^{2} U}{\partial H \partial C}=\psi(1-\psi)(1-\gamma) C^{\psi(1-\gamma)-1} H^{(1-\psi)(1-\gamma)-1}
$$

which is negative if $\gamma>1$, zero if $\gamma=1$, and positive if $\gamma<1$. Intuitively, the sign of the cross partial is critical for portfolio choice for the same reason it is important for optimal health insurance, as discussed earlier. If $\gamma>1$, the cross partial is negative, and a decline in health raises the marginal utility of consumption as well as the marginal utility of health. Risks to health compound risks to consumption, and the optimal amount of health insurance is greater than the actuarially fair amount required to treat health shocks. If health risks are uninsurable, the individual decreases his or her financial risks. When $0<\gamma<1$, all this logic reverses. Risks to health actually diminish risks to consumption, and investors increase their financial risk in response to risky health. As discussed previously, the magnitude of $\gamma$ is theoretically ambiguous, and there is disagreement among empirical studies seeking to 
measure it. But the results of Lillard and Weiss (1997) imply that the cross partial should be negative among the elderly investors.

\section{Discussion}

This paper explores the implications for portfolio choice of a special type of state-dependent utility. If individuals care about health and consumption with a nonzero cross partial derivative of utility, then the specter of health shocks should influence life-cycle portfolio choice through their direct impacts on the future demand for money. Empirical evidence on the sign of the cross partial is mixed, but the variation in results across age groups is consistent with a sign that changes depending on age-specific health conditions. For older investors who face risks of debilitating illnesses that impede home production, a negative cross partial is a plausible characteristic with some empirical support. This paper shows that when the cross partial is negative, investors who feel their health is risky will hedge by holding less risky financial portfolios.

In reality, the risk of poor health not only varies across individuals, as my stylized model allows, it probably also varies systematically across age. Mortality risk increases exponentially with age, poor health typically precedes death, and the years just prior to death are the most expensive in terms of health costs (Miller, 2001). The implications of this dynamic, which is practically impossible to model formally while preserving the ability to find a closed-form solution, can instead be inferred from the literature on precautionary saving. As discussed by Hubbard et al. (1994), the optimal response to exponentially rising mortality risk is to increase precautionary saving throughout the life cycle and to plan a diminishing consumption trajectory that roughly tracks waning survivorship probabilities. The analogous implication here is that investors who expect $\pi_{h}$ to rise over time should take on less financial risk throughout life, with an especially steep reduction toward the end of life if $\pi_{h}$ follows the age-trajectory of mortality. In a companion paper, Edwards (2008) assesses the 
empirical fit of the model using data on self-reported $\pi_{h}$ from the Health and Retirement Study. Results suggest that health risk may explain 20 percent of the age-related decline in financial risk taking after retirement.

To be sure, variability in the prices of medical care, or equivalently in spending on health, probably also changes the composition of savings and not just its level. This runs contrary to the implications of the stylized model I consider here. Because I have specified generalized Cobb-Douglas preferences over health and consumption with constant relative risk aversion, and because health care price inflation is IID, volatility in health spending only affects precautionary saving and not portfolio choice. Given the theoretical and empirical findings in the literature on portfolio choice in the presence of background risks, it seems likely that health care cost risk should also trigger safer portfolios. Separating the effects of medical expenditure risk and the direct effects of health on utility is a challenge for future research.

There are several broader implications of the theoretical results presented here and the empirical findings in Edwards (2008). Given that risky health diminishes financial risk taking, a response that is clearly second-best, it raises the question of why individuals are underinsured against risky health in the first place. To be sure, if full health insurance triggered moral hazard or overutilization, two dynamics completely outside the stylized model I consider, a system of partial insurance could actually be socially preferable. Adverse selection could yield an equilibrium of partial insurance in private markets with many insurers, although it is hard to see how such an equilibrium could be Pareto optimal. In any event, most broadly marketed forms of health insurance compensate individuals for particular medical goods and services in kind rather than simply paying cash in the unhealthy state. If the cross partial is negative for retirees, they would optimally prefer health insurance that paid cash, in excess of the actuarially fair amount of medical insurance, to help them also replace home production when sick. Long-term care insurance might partially fulfill this need, insuring against some catastrophic losses of home production by funding at-home care, but these markets are underdeveloped. 
An aggregate implication of these findings is that what may otherwise appear to be suboptimal financial risk taking may be a rational response to undiversifiable health risk. Due to life-cycle saving, older investors hold a large share of national savings. To the extent risky health is a necessary byproduct of aging, an aggregate portfolio that seems too weighted toward safe assets given the size of the equity risk premium and the covariance of returns with consumption (Mehra and Prescott, 1985) could be due in part to risky health. Injecting more risk into Social Security through privatization in order to exploit the equity risk premium could be very counterproductive if older investors are intentionally holding safer portfolios. Such reform may only be desirable if it were coupled with Medicare expansion.

\section{Appendix}

\section{A The log-linear budget constraints}

When health must be purchased. Dividing both sides of (4) by $W_{t}$, substituting for the price of health using (6), taking logs, and denoting logs in lowercase produces

$$
w_{t+1}-w_{t}=\log \left(1-e^{c_{t}-w_{t}}-e^{h_{t}+\sum_{s=0}^{t} r_{h, s}-w_{t}}\right)+r_{p, t+1} .
$$

The next step is to take a first-order Taylor approximation of the first term on the right-hand

side around the mean values of $c_{t}-w_{t}$ and $h_{t}+\sum_{s=0}^{t} r_{h, s}-w_{t}$. Naming those two variables $X_{t}$ and $Y_{t}$ for shorthand, one can write the expansion as

$$
\begin{aligned}
& \log \left(1-e^{X_{t}}-e^{Y_{t}}\right) \approx \log \left(1-e^{E\left[X_{t}\right]}-e^{E\left[Y_{t}\right]}\right)+\frac{1}{1-e^{E\left[X_{t}\right]}-e^{E\left[Y_{t}\right]}} \times \\
& \left(-e^{E\left[X_{t}\right]}\right)\left(X_{t}-E\left[X_{t}\right]\right)+\frac{1}{1-e^{E\left[X_{t}\right]}-e^{E\left[Y_{t}\right]}} \times\left(-e^{E\left[Y_{t}\right]}\right)\left(Y_{t}-E\left[Y_{t}\right]\right) .
\end{aligned}
$$


The log-linear budget constraint for older investors is therefore

$$
w_{t+1}-w_{t}=k-\rho_{c}\left(c_{t}-w_{t}\right)-\rho_{h}\left(h_{t}+\sum_{s=0}^{t} r_{h, s}-w_{t}\right)+r_{p, t+1}
$$

where $k$ is a constant that can be inferred by collecting terms in (32), and $\rho_{c}$ and $\rho_{h}$ are given by

$$
\begin{aligned}
\rho_{c} & =\frac{e^{E\left[c_{t}-w_{t}\right]}}{1-e^{E\left[c_{t}-w_{t}\right]}-e^{E\left[h_{t}+\sum_{s=0}^{t} r_{h, s}-w_{t}\right]}}, \\
\rho_{h} & =\frac{e^{E\left[h_{t}+\sum_{s=0}^{t} r_{h, s}-w_{t}\right]}}{1-e^{E\left[c_{t}-w_{t}\right]}-e^{E\left[h_{t}+\sum_{s=0}^{t} r_{h, s}-w_{t}\right]}} .
\end{aligned}
$$

The numerators in each formula for the $\rho$ 's are positive by construction. Since wealth can never be less than consumption and health costs, the denominators are also positive, implying that $\rho_{c}>0$ and $\rho_{h}>0$.

When health is an endowment. Following the same steps as in the previous section, one can show that the log-linear budget constraint based on (3) is

$$
w_{t+1}-w_{t}=k^{h}-\rho_{c}^{h}\left(c_{t}^{h}-w_{t}\right)+r_{p, t+1}
$$

where $k^{h}$ is a constant and $\rho^{h}$ is given by

$$
\rho_{c}^{h}=\frac{e^{E\left[c_{t}^{h}-w_{t}\right]}}{1-e^{E\left[c_{t}^{h}-w_{t}\right]}}
$$

This is identical to the log-linear budget constraint found in Campbell (1993) and Campbell and Viceira (1999). 


\section{B Finding the log-linear Euler equations}

When health must be purchased. Consider the health Euler equation, (12). If $\mathbf{X} \sim$ $L N\left(\mu, \sigma^{2}\right)$ is given by

$$
\mathbf{X}=\delta \frac{1}{R_{h, t+1}}\left(\frac{H_{t+1}}{H_{t}}\right)^{(1-\psi)(1-\gamma)-1}\left(\frac{C_{t+1}}{C_{t}}\right)^{\psi(1-\gamma)} R_{i, t+1}
$$

then since $\log \mathbf{X} \sim N\left(\mu, \sigma^{2}\right)$ and $E_{t}[\mathbf{X}]=e^{\mu+\sigma^{2} / 2}$,

$$
\begin{aligned}
\log E_{t}[\mathbf{X}]= & \log \delta+E_{t}\left[r_{i, t+1}\right]-E_{t}\left[r_{h, t+1}\right]+\beta_{3} E_{t}\left[h_{t+1}-h_{t}\right]+\beta_{4} E_{t}\left[c_{t+1}-c_{t}\right] \\
& +\frac{1}{2} \operatorname{Var}_{t}\left[r_{i, t+1}-r_{h, t+1}+\beta_{3}\left(h_{t+1}-h_{t}\right)+\beta_{4}\left(c_{t+1}-c_{t}\right)\right] .
\end{aligned}
$$

Repeating these steps for (11), the consumption Euler equation, produces the log-linearized Euler equations, (13) and (14).

When there is a risk of purchasing health. Following Viceira (2001) the log-linear Euler approximation is derived using several Taylor approximations. This technique is required because the right-hand side is a sum rather than a product of expectations of lognormal variables. Notational shorthand transforms (20) into

$$
1=\left(1-\pi_{h}\right) E_{t}\left[e^{x_{t+1}}\right]+\pi_{h} E_{t}\left[e^{y_{t+1}}\right]
$$

Taking second-order Taylor expansions around $\bar{x}_{t+1}$ and $\bar{y}_{t+1}$, moving the constant multiples out from behind the expectations operator, distributing the expectation, and simplifying yields

$$
1 \approx\left(1-\pi_{h}\right) e^{\bar{x}_{t+1}}\left(1+\frac{1}{2} \operatorname{Var}_{t}\left[x_{t+1}\right]\right)+\pi_{h} e^{\bar{y}_{t+1}}\left(1+\frac{1}{2} \operatorname{Var}_{t}\left[y_{t+1}\right]\right)
$$


A first-order expansion of $e^{\bar{z}} \approx 1+\bar{z}$ can now be used, implying

$$
\begin{aligned}
1 \approx & \left(1-\pi_{h}\right)\left(1+\bar{x}_{t+1}+\frac{1}{2} \operatorname{Var}_{t}\left[x_{t+1}\right]+\bar{x}_{t+1} \frac{1}{2} \operatorname{Var}_{t}\left[x_{t+1}\right]\right) \\
& +\pi_{h}\left(1+\bar{y}_{t+1}+\frac{1}{2} \operatorname{Var}_{t}\left[y_{t+1}\right]+\bar{y}_{t+1} \frac{1}{2} \operatorname{Var}_{t}\left[y_{t+1}\right]\right) .
\end{aligned}
$$

If $\bar{x}_{t+1}, \bar{y}_{t+1}$ and the variance terms are small, then their products are second-order small and can be omitted, and 1 can be subtracted from both sides, yielding

$$
0 \approx\left(1-\pi_{h}\right)\left(\bar{x}_{t+1}+\frac{1}{2} \operatorname{Var}_{t}\left[x_{t+1}\right]\right)+\pi_{h}\left(\bar{y}_{t+1}+\frac{1}{2} \operatorname{Var}_{t}\left[y_{t+1}\right]\right)
$$

Substituting for $x_{t+1}$ and $y_{t+1}$ and combining terms produces (21) in the text.

\section{Proof of Proposition 1}

Euler differences. The standard approach is to examine the difference between Euler conditions for the risky and for the risk-free asset. Subtracting the log-linear Euler equation for health (14) with $i=f$ from (14) with $i=1$ yields, after cancellations and two expansions of variance terms:

$$
0=E_{t}\left[r_{1, t+1}\right]-r_{f}+\frac{1}{2} \sigma_{r}^{2}+\operatorname{Cov}_{t}\left[r_{1, t+1}, \beta_{3} \Delta h_{t+1}+\beta_{4} \Delta c_{t+1}\right] .
$$

By extension, differencing the consumption log Euler condition (13) between $i=1, f$ results in a second Euler difference:

$$
0=E_{t}\left[r_{1, t+1}\right]-r_{f}+\frac{1}{2} \sigma_{r}^{2}+\operatorname{Cov}_{t}\left[r_{1, t+1}, \beta_{1} \Delta c_{t+1}+\beta_{2} \Delta h_{t+1}\right] .
$$


Solving for $\alpha$. Comparing (44) to (45), it is clear that if both Euler conditions hold, then there must be a relationship between the covariances:

$$
\operatorname{Cov}_{t}\left[r_{1, t+1}, \beta_{3} \Delta h_{t+1}+\beta_{4} \Delta c_{t+1}\right]=\operatorname{Cov}_{t}\left[r_{1, t+1}, \beta_{1} \Delta c_{t+1}+\beta_{2} \Delta h_{t+1}\right]
$$

Expanding terms and observing that $\left(\beta_{1}-\beta_{4}\right) /\left(\beta_{3}-\beta_{2}\right)=1$ implies

$$
\operatorname{Cov}_{t}\left[r_{1, t+1}, \Delta c_{t+1}\right]=\operatorname{Cov}_{t}\left[r_{1, t+1}, \Delta h_{t+1}\right]
$$

Combining (47) with (45) after expanding the covariance term produces

$$
E_{t}\left[r_{1, t+1}\right]-r_{f}+\frac{1}{2} \sigma_{r}^{2}=-\left(\beta_{1}+\beta_{2}\right) \operatorname{Cov}_{t}\left[r_{1, t+1}, \Delta c_{t+1}\right]
$$

Combining (9) and (10) with first (15) and then (16) implies

$$
\begin{aligned}
& \operatorname{Cov}_{t}\left[r_{1, t+1}, \Delta c_{t+1}\right]=b_{c, 1}^{u} \alpha \sigma_{r}^{2}, \\
& \operatorname{Cov}_{t}\left[r_{1, t+1}, \Delta h_{t+1}\right]=b_{h, 1}^{u} \alpha \sigma_{r}^{2} .
\end{aligned}
$$

But since (47) holds, it must be true that $b_{c, 1}^{u}=b_{h, 1}^{u}$. Rearranging (48) then implies that the optimal portfolio split is

$$
\alpha_{t}=\frac{E_{t}\left[r_{1, t+1}\right]-r_{f}+\frac{1}{2} \sigma_{r}^{2}}{-\left(\beta_{1}+\beta_{2}\right) b_{c, 1}^{u} \sigma_{r}^{2}} .
$$

Solving for the rule parameters. To solve for $b_{c, 1}^{u}=b_{h, 1}^{u}$, first note that the rules (15) and (16) imply that

$$
\begin{aligned}
E_{t}\left[c_{t+1}-c_{t}\right] & =b_{c, 1}^{u} E_{t}\left[w_{t+1}-w_{t}\right], \\
E_{t}\left[h_{t+1}-h_{t}\right]+E_{t}\left[r_{h, t+1}\right] & =b_{h, 1}^{u} E_{t}\left[w_{t+1}-w_{t}\right] .
\end{aligned}
$$


Together, these two equations imply a relationship between expected consumption growth and expected health growth:

$$
E_{t}\left[h_{t+1}-h_{t}\right]+E_{t}\left[r_{h, t+1}\right]=\frac{b_{h, 1}^{u}}{b_{c, 1}^{u}} E_{t}\left[c_{t+1}-c_{t}\right] .
$$

In light of (54), the log Euler equation for health (14) with $i=p$ implies

$$
\begin{array}{r}
\log \delta+E_{t}\left[r_{p, t+1}\right]-E_{t}\left[r_{h, t+1}\right]+\left(\beta_{3} \frac{b_{h, 1}^{u}}{b_{c, 1}^{u}}+\beta_{4}\right) E_{t}\left[c_{t+1}-c_{t}\right]-\beta_{3} E_{t}\left[r_{h, t+1}\right] \\
+\frac{1}{2} \operatorname{Var}_{t}\left[r_{p, t+1}-r_{h, t+1}+\beta_{3}\left(h_{t+1}-h_{t}\right)+\beta_{4}\left(c_{t+1}-c_{t}\right)\right]=0
\end{array}
$$

while the $\log$ Euler equation for consumption (13) with $i=p$ becomes

$$
\begin{array}{r}
\log \delta+E_{t}\left[r_{p, t+1}\right]+\left(\beta_{1}+\beta_{2} \frac{b_{h, 1}^{u}}{b_{c, 1}^{u}}\right) E_{t}\left[c_{t+1}-c_{t}\right]-\beta_{2} E_{t}\left[r_{h, t+1}\right] \\
+\frac{1}{2} \operatorname{Var}_{t}\left[r_{p, t+1}+\beta_{1}\left(c_{t+1}-c_{t}\right)+\beta_{2}\left(h_{t+1}-h_{t}\right)\right]=0 .
\end{array}
$$

Combining the log-linear budget constraint and the choice rules implies

$$
E_{t}\left[\Delta w_{t+1}\right]=k-\rho_{c} b_{c, 0}^{u}-\rho_{h} b_{h, 0}^{u}+\left(\rho_{c}+\rho_{h}-\rho_{c} b_{c, 1}^{u}-\rho_{h} b_{h, 1}^{u}\right) w_{t}+E_{t}\left[r_{p, t+1}\right]
$$

Substituting for $E_{t}\left[c_{t+1}-c_{t}\right]$ in (55) using (52) and (57) and noting that $\beta_{3}+1=\beta_{2}$ results in a single equation in $w_{t}$ :

$$
\begin{aligned}
& \mathcal{A}\left(-\log \delta-E_{t}\left[r_{p, t+1}\right]+\beta_{2} E_{t}\left[r_{h, t+1}\right]\right) \\
& -\frac{1}{2} \mathcal{A} \operatorname{Var}_{t}\left[r_{p, t+1}-r_{h, t+1}+\beta_{3}\left(h_{t+1}-h_{t}\right)+\beta_{4}\left(c_{t+1}-c_{t}\right)\right] \\
& =k-\rho_{c} b_{c, 0}^{u}-\rho_{h} b_{h, 0}^{u}+\left(\rho_{c}+\rho_{h}-\rho_{c} b_{c, 1}^{u}-\rho_{h} b_{h, 1}^{u}\right) w_{t}+E_{t}\left[r_{p, t+1}\right],
\end{aligned}
$$

where $\mathcal{A}=\left(1 / b_{c, 1}^{u}\right) /\left(\beta_{3}\left(b_{h, 1}^{u} / b_{c, 1}^{u}\right)+\beta_{4}\right)$. Since $w_{t}$ cannot be constant, it follows that its coefficient, $\rho_{c}\left(1-b_{c, 1}^{u}\right)+\rho_{h}\left(1-b_{h, 1}^{u}\right)=0$, is zero. As shown previously, $b_{c, 1}^{u}=b_{h, 1}^{u}$. Since the 
$\rho$ 's are both positive, the only solution is that $b_{c, 1}^{u}=b_{h, 1}^{u}=1$.

There is currently only one equation, (58), in the two unknowns, $b_{c, 0}^{u}$ and $b_{h, 0}^{u}$. A second relationship is $b_{c, 0}^{u}=b_{h, 0}^{u}[\psi /(1-\psi)]$, which follows directly from the fact that preferences are Cobb-Douglas over health and consumption. Combining this with (58), accounting for $b_{c, 1}^{u}=b_{h, 1}^{u}=1$, using the consumption rules and the log-linear budget constraint, and simplifying yields an equation for the target ratio of health spending to wealth:

$$
\begin{aligned}
b_{h, 0}^{u}= & \frac{\mathcal{A}}{\mathcal{B}}\left(\log \delta-\beta_{2} E_{t}\left[r_{h, t+1}\right]\right)+\frac{\mathcal{A}+1}{\mathcal{B}} E_{t}\left[r_{p, t+1}\right]+\frac{k}{\mathcal{B}} \\
& +\frac{\mathcal{A}}{2 \mathcal{B}}\left(1+\beta_{3}+\beta_{4}\right)^{2} \operatorname{Var}_{t}\left[r_{p, t+1}\right]+\frac{\mathcal{A}}{2 \mathcal{B}} \beta_{2}^{2} \operatorname{Var}_{t}\left[r_{h, t+1}\right],
\end{aligned}
$$

and an equation for the target consumption-wealth ratio:

$$
\begin{aligned}
b_{c, 0}^{u}= & \frac{\mathcal{A}}{\mathcal{C}}\left(\log \delta-\beta_{2} E_{t}\left[r_{h, t+1}\right]\right)+\frac{\mathcal{A}+1}{\mathcal{C}} E_{t}\left[r_{p, t+1}\right]+\frac{k}{\mathcal{C}} \\
& +\frac{\mathcal{A}}{2 \mathcal{C}}\left(1+\beta_{3}+\beta_{4}\right)^{2} \operatorname{Var}_{t}\left[r_{p, t+1}\right]+\frac{\mathcal{A}}{2 \mathcal{C}} \beta_{2}^{2} \operatorname{Var}_{t}\left[r_{h, t+1}\right],
\end{aligned}
$$

where $\mathcal{A}=\left(\beta_{3}+\beta_{4}\right)^{-1}=-1 / \gamma, \mathcal{B}=\rho_{c} \frac{\psi}{(1-\psi)}+\rho_{h}$, and $\mathcal{C}=\rho_{c}+\rho_{h} \frac{(1-\psi)}{\psi}$. Since $\gamma>0$, $\mathcal{A}<0$, and since $\psi, \rho_{c}, \rho_{h}>0, \mathcal{B}>0$ and $\mathcal{C}>0$. By inspection, $b_{c, 0}^{u}$ and $b_{h, 0}^{u}$ both fall with increased variability in $r_{p, t+1}$ or $r_{h, t+1}$, because $\mathcal{A} / 2 \mathcal{B}$ and $\mathcal{A} / 2 \mathcal{C}$ are both negative. These are precautionary saving effects: increases in background variance cause the individual to save more.

\section{Proof of Proposition 2}

Euler differences. As with unhealthy investors, the strategy is to obtain a relationship for the risk premium by differencing the log Euler equation, (21), through asset types 1 and $f$. Since there is no variability in health growth, $h_{t+1}^{h}-h_{t}^{h}$ drops out of the variance terms, as does $r_{f}$, and expanding the variance terms produces a separate $\sigma_{r}^{2}$ term and more 
cancellations:

$$
\begin{aligned}
0= & E_{t}\left[r_{1, t+1}\right]-r_{f}+\frac{1}{2} \sigma_{r}^{2}+\left(1-\pi_{h}\right) \operatorname{Cov}_{t}\left[r_{1, t+1}, \beta_{1}\left(c_{t+1}^{h}-c_{t}^{h}\right)\right] \\
& +\pi_{h} \operatorname{Cov}_{t}\left[r_{1, t+1}, \beta_{1}\left(c_{t+1}-c_{t}^{h}\right)+\beta_{2}\left(h_{t+1}-h_{t}^{h}\right)\right]
\end{aligned}
$$

The second covariance in (61) has already been solved in Appendix C. The first covariance can be found by rewriting (22):

$$
c_{t+1}^{h}-c_{t}^{h}=b_{c, 1}^{h}\left(w_{t+1}-w_{t}\right) .
$$

Combining (62) with (8) and (10) implies

$$
\operatorname{Cov}_{t}\left[r_{1, t+1}, \beta_{1}\left(c_{t+1}^{h}-c_{t}^{h}\right)\right]=\beta_{1} b_{c, 1}^{h} \alpha \sigma_{r}^{2}
$$

and combining (63), $b_{c, 1}^{u}=1$, and (61) yields

$$
\alpha_{t}^{h}=\frac{E_{t}\left[r_{1, t+1}\right]-r_{f}+\frac{1}{2} \sigma_{r}^{2}}{-\left[\left(1-\pi_{h}\right) \beta_{1} b_{c, 1}^{h}+\pi_{h}\left(\beta_{1}+\beta_{2}\right)\right] \sigma_{r}^{2}} .
$$

Finding the rule parameters. The log-linear Euler approximation (21) for $i=p$ can be combined with the three optimal rules (one for healthy investors, two for unhealthy investors) to produce

$$
\begin{aligned}
0= & \log \delta+E_{t}\left[r_{p, t+1}\right]+\left(1-\pi_{h}\right) \beta_{1} b_{c, 1}^{h} E_{t}\left[\Delta w_{t+1}\right]+\left(1-\pi_{h}\right) \beta_{2} g \\
& +\frac{1-\pi_{h}}{2} \operatorname{Var}_{t}\left[r_{p, t+1}+\beta_{1} b_{c, 1}^{h} \Delta w_{t+1}+\beta_{2} g\right] \\
& +\pi_{h} \beta_{1} E_{t}\left[\Delta w_{t+1}\right]+\pi_{h} \beta_{2} E_{t}\left[\Delta w_{t+1}\right] \\
& +\frac{\pi_{h}}{2} \operatorname{Var}_{t}\left[r_{p, t+1}+\beta_{1} \Delta w_{t+1}+\beta_{2} \Delta w_{t+1}\right]
\end{aligned}
$$


where $b_{c, 1}^{u}=b_{h, 1}^{u}=1$ has been used. In the first two lines of (65), the single-good budget constraint (8) holds, and in the second two lines, the two-good budget constraint is relevant. Substituting for $E_{t}\left[\Delta w_{t+1}\right]$, health spending, and consumption using the budget constraint and the three consumption rules, distributing the expectations operator, and simplifying the variance and $w_{t}$ terms yields

$$
\begin{aligned}
0= & \log \delta+E_{t}\left[r_{p, t+1}\right]+\left(1-\pi_{h}\right) \beta_{1}\left(b_{c, 1}^{h} k^{h}-\rho_{c}^{h}\left(b_{c, 0}^{h}+\left(b_{c, 1}^{h}-1\right) w_{t}\right)+E_{t}\left[r_{p, t+1}\right]\right) \\
& +\left(1-\pi_{h}\right) \beta_{2} g+\frac{1-\pi_{h}}{2}\left(1+\beta_{1} b_{c, 1}^{h}\right)^{2} \operatorname{Var}_{t}\left[r_{p, t+1}\right] \\
& +\pi_{h}\left(\beta_{1}+\beta_{2}\right)\left(k-\rho_{c} b_{c, 0}^{u}-\rho_{h} b_{h, 0}^{u}+E_{t}\left[r_{p, t+1}\right]\right) \\
& +\frac{\pi_{h}}{2}\left(1+\beta_{1}+\beta_{2}\right)^{2} \operatorname{Var}_{t}\left[r_{p, t+1}\right] .
\end{aligned}
$$

By inspection, (66) is a single equation in $w_{t}$ and the fixed parameters. Since $w_{t}$ cannot be constant, it follows that its coefficient, $\left(1-\pi_{h}\right) \beta_{1} \rho_{c}^{h}\left(b_{c, 1}^{h}-1\right)$, must be zero. Since $\pi_{h} \neq 1$, $\rho_{c}^{h}>0$, and $\beta_{1}=\psi(1-\gamma)-1 \neq 0$ as long as $\psi \neq 1 /(1-\gamma)$, the only solution is that $b_{c, 1}^{h}=1$.

To find $b_{c, 0}^{h}, b_{c, 1}^{h}=1$ can be substituted into (66):

$$
\begin{aligned}
b_{c, 0}^{h}= & \mathcal{D} \log \delta+\mathcal{D}\left(1+\beta_{1}+\left(1-\pi_{h}\right) \beta_{2}\right) E_{t}\left[r_{p, t+1}\right]+\mathcal{D}\left(1-\pi_{h}\right) \beta_{1} k^{h} \\
& +\mathcal{D}\left(1-\pi_{h}\right) \beta_{2} g+\mathcal{D} \pi_{h}\left(\beta_{1}+\beta_{2}\right)\left(k-\rho_{c} b_{c, 0}^{u}-\rho_{h} b_{h, 0}^{u}\right) \\
& +\mathcal{D}\left(\frac{\pi_{h}}{2}\left(1+\beta_{1}+\beta_{2}\right)^{2}+\frac{1-\pi_{h}}{2}\left(1+\beta_{1}\right)^{2}\right) \operatorname{Var}_{t}\left[r_{p, t+1}\right]
\end{aligned}
$$

where $\mathcal{D}=1 /\left[\left(1-\pi_{h}\right) \beta_{1} \rho_{c}^{h}\right]<0$ since $\beta_{1}<0$.

Financial risk exerts two countervailing effects on $b_{c, 0}^{h}$. A rise in $\sigma_{r}^{2}$ decreases $b_{c, 0}^{h}$ and raises precautionary saving while healthy. But rising variance also lowers $b_{c, 0}^{u}$ and $b_{h, 0}^{u}$, increasing precautionary saving when unhealthy and lowering it when healthy. An increase in health inflation variance also lowers $b_{c, 0}^{u}$ and $b_{h, 0}^{u}$ but has no countervailing direct impact on $b_{c, 0}^{h}$. An increase in health inflation variance thus increases $b_{c, 0}^{h}$ and lowers precautionary saving when healthy, presumably because unhealthy investors save more. 
The effect of health risk on saving, $\partial b_{c, 0}^{h} / \partial \pi_{h}$, is of indeterminate sign because it depends on the signs and relative sizes of $k, k^{h}, b_{c, 0}^{u}$, and $b_{h, 0}^{u}$. The results of numerically solved models of precautionary saving (Hubbard et al., 1994; Palumbo, 1999) suggest that it is likely to be negative for reasonable parameter values. 


\section{References}

Ameriks, J., and S. P. Zeldes (2004), "How do household portfolio shares vary with age?" Working paper, September.

Bommier, A., and G. Stecklov (2002), "Defining health inequality: Why Rawls succeeds where social welfare theory fails," Journal of Health Economics 21, 497-513.

Campbell, J. Y. (1993), "Intertemporal asset pricing without consumption data," American Economic Review 83, 487-512.

Campbell, J. Y., A. W. Lo, and A. C. MacKinlay (1997), The Econometrics of Financial Markets, Princeton, NJ: Princeton University Press.

Campbell, J. Y., and L. M. Viceira (1999), "Consumption and portfolio decisions when expected returns are time varying," Quarterly Journal of Economics 114, 433-495.

Campbell, J. Y., and L. M. Viceira (2002), Strategic Asset Allocation: Portfolio Choice for Long-Term Investors, Oxford: Oxford University Press.

Cocco, J. F., F. J. Gomes, and P. J. Maenhout (2005), "Consumption and portfolio choice over the life cycle," Review of Financial Studies 18, 491-533.

Dynan, K. E., J. Skinner, and S. P. Zeldes (2004), "Do the rich save more?" Journal of Political Economy 112, 397-444.

Edwards, R. D. (2008), "Health risk and portfolio choice," Journal of Business and Economic Statistics 26, 472-485.

Elmendorf, D. W., and M. S. Kimball (2000), "Taxation of labor income and the demand for risky assets," International Economic Review 41, 801-832.

Evans, W. N., and W. K. Viscusi (1991), "Estimation of state-dependent utility functions using survey data," Review of Economics and Statistics 73, 94-104. 
Finkelstein, A., E. Luttmer, and M. J. Notowidigdo (2008), "What good is wealth without health? The effect of health on the marginal utility of consumption," NBER Working Paper 14089 .

French, E., and J. B. Jones (2004), "On the distribution and dynamics of health care costs," Journal of Applied Econometrics 19, 705-721.

Gollier, C., and J. W. Pratt (1996), "Risk vulnerability and the tempering effect of background risk," Econometrica 64, 1109-1123.

Grossman, M. (1972), "On the concept of health capital and the demand for health," Journal of Political Economy 80, 223-255.

Guiso, L., M. Haliassos, and T. Jappelli, eds. (2002), Household Portfolios, Cambridge, MA: MIT Press.

Guiso, L., T. Jappelli, and D. Terlizzese (1996), "Income risk, borrowing constraints, and portfolio choice," American Economic Review 86, 158-172.

Hansen, L. P., and K. J. Singleton (1983), "Stochastic consumption, risk aversion, and the temporal behavior of asset returns," Journal of Political Economy 91, 249-265.

Heaton, J., and D. Lucas (2000), "Portfolio choice in the presence of background risk," The Economic Journal 110, 1-26.

Hubbard, R. G., J. Skinner, and S. P. Zeldes (1994), "The importance of precautionary motives in explaining individual and aggregate saving," Carnegie-Rochester Conference Series on Public Policy 40, 59-125.

Ibbotson, R. G., and P. D. Kaplan (2000), "Does asset allocation policy explain 40, 90, or 100 percent of performance?" Financial Analysts Journal 56, 26-33. 
Jagannathan, R., and N. R. Kocherlakota (1996), "Why should older people invest less in stocks than younger people?" Federal Reserve Bank of Minneapolis Quarterly Review 20, $11-23$.

Kimball, M. S. (1992), "Precautionary motives for holding assets," in P. Newman, M. Milgate, and J. Eatwell, eds., "The New Palgrave Dictionary of Money and Finance," volume 3, 158-161, New York: Stockton Press.

Lillard, L. A., and Y. Weiss (1997), "Uncertain health and survival: Effects on end-of-life consumption," Journal of Business and Economic Statistics 15, 254-268.

Malkiel, B. G. (1999), A Random Walk Down Wall Street: Including a Life-Cycle Guide to Personal Investing, New York: Norton, 7th edition.

Mehra, R., and E. C. Prescott (1985), "The equity premium: A puzzle," Journal of Monetary Economics 14, 145-161.

Merton, R. C. (1969), "Lifetime portfolio selection under uncertainty: The continuous-time case," Review of Economics and Statistics 51, 247-257.

Merton, R. C. (1971), "Optimum consumption and portfolio rules in a continuous-time model," Journal of Economic Theory 3, 373-413.

Miller, T. (2001), "Increasing longevity and medicare expenditures," Demography 38, 215226.

Palumbo, M. G. (1999), "Uncertain medical expenses and precautionary saving near the end of the life cycle," Review of Economic Studies 66, 395-421.

Picone, G., M. Uribe, and M. R. Wilson (1998), "The effect of uncertainty on the demand for medical care, health capital and wealth," Journal of Health Economics 17, 171-185.

Rosen, H. S., and S. Wu (2004), "Portfolio choice and health status," Journal of Financial Economics 72, 457-484. 
Samuelson, P. A. (1969), "Lifetime portfolio selection by dynamic stochastic programming," Review of Economics and Statistics 51, 239-246.

Samuelson, P. A. (1974), "Complementarity: An essay on the 40th anniversary of the HicksAllen Revolution in demand theory," Journal of Economic Literature 12, 1255-1289.

Samuelson, P. A. (1989), "A case at last for age-phased reductions in equity," Proceedings of the National Academy of Sciences 86, 9048-9051.

Siegel, J. (1994), Stocks for the Long Run, New York: McGraw Hill.

Smith, J. P. (1999), "Healthy bodies and thick wallets: The dual relation between health and economic status," Journal of Economic Perspectives 13, 145-166.

Viceira, L. M. (2001), "Optimal portfolio choice for long-horizon investors with nontradable labor income," Journal of Finance 56, 433-470.

Viscusi, W. K., and W. N. Evans (1990), "Utility functions that depend on health status: Estimates and economic implications," American Economic Review 80, 353-374. 